\title{
O INDÍGENA NO IMAGINÁRIO ALEGÓRICO DOS BUMBÁS DE PARINTINS
}

\section{The indigenous in the allegorical imaginary of Parintins' bumbás}

\author{
Ericky da Silva Nakanome \\ Adan Renê Pereira da Silva \\ Universidade Federal do Amazonas
}

\begin{abstract}
Resumo: Alegoria é um cenário móvel, suporte cenográfico para apresentação de parte do espetáculo dos bumbás. O estudo objetivou compreender a construção do indígena no imaginário alegórico do boi-bumbá de Parintins, Amazonas, Brasil, por meio de pesquisa etnográfica, focando-se no ritual indígena. O resultado evidencia a mescla do parintinense indígena e construtor da festa, tornando a visão do índio romantizada e espetacularizada simultaneamente.
\end{abstract}

Palavras-chave: Indígena, Festival de Parintins, imaginário alegórico.

Abstract: Allegory is a mobile scenario, scenographic support for presentation of part of the spectacle of the bumbás. The study aimed to understand the construction of the indigenous in the allegorical imagery of the boi-bumbá of Parintins, Amazonas, Brazil, through ethnographic research, focusing on the indigenous ritual. The result evidences the mixture of the indigenous parintinense and party builder, making the vision of the Indian romanticized and spectacular simultaneously.

Keywords: Indigenous, Parintins Festival, allegorical imagery. 
O espetáculo apresentado pelos bumbás Caprichoso e Garantido na cidade de Parintins, Amazonas, permitiu que o município ganhasse notoriedade no cenário cultural brasileiro e também reconhecimento no contexto internacional, tornando o "boi" um produto por meio do qual a comunidade teceu sua identidade regional.

A formação sociocultural parintinense, gerada pelo processo de miscigenação, tem como base o posicionamento geográfico de passagem de rio e caminho entre as capitais Manaus (AM) e Belém (PA). No meio amazônico, inúmeras comunidades indígenas, de europeus, descendentes de africanos, de judeus, de árabes e de japoneses se entrelaçaram em uma tessitura que deu origem a uma cultura cabocla singular, caracterizada por folguedos originados do Velho Mundo, costumes orientais, batuques africanos, falas e costumes indígenas que sobreviveram ao tempo e às transformações sociais, sendo

vivenciados

na

contemporaneidade.

Neste mosaico, encontra-se a brincadeira de boi, conhecida em todo o Brasil e celebrada em suas vertentes plurais. No norte do país, a brincadeira redefiniu-se e redimensionou-se, deixando de comportar-se e de apresentar-se como "Bumba meu boi". A manifestação originada no Nordeste Ihe serve de base, para consolidar-se como "Boi-Bumbá da Amazônia", uma tradução original dessa modalidade de folguedo junino. Uma das grandes diferenças do bumba meu boi nordestino em relação à sua versão nortista é a presença acentuada do indígena, que integra seu contexto cênico desde a fase de brincadeira de terreiro até a que vislumbramos na atualidade.

A importância e a complexidade assumidas pela temática indígena podem ser vistas como a reafirmação de sua importância na formação social e cultural cabocla da região norte e também na construção de uma identidade amazônica. A preponderância da figura e dos 
assuntos indígenas no enredo das apresentações reconfigurou a antiga brincadeira de rua, ao descortinar um rico e inesgotável universo do índio no Auto do boi.

O universo indígena e sua produção estética, abordados artisticamente nos principais momentos do espetáculo dos bumbás, exprime uma carga exótica e heroica. Muitos estudiosos (Sociologia, Antropologia, entre outras áreas) debruçaram-se sobre a temática. No entanto, poucas são as pesquisas interessadas na compreensão da festa com foco em suas representações artísticas.

A pesquisa mostra-se relevante, na medida em que pensa o confronto das matrizes culturais do Brasil no Auto do boi, buscando o entendimento das bases étnicas da festa, onde a figura indígena ganha maior importância. Vale lembrar que o discurso pop em torno do indígena, em todo o Brasil, revelou personalidades, como o cacique Raoni Metuktire, porta-voz dos grupos caiapó, e o xavante Mário Juruna, eleito deputado estadual de São Paulo, em 1983, e outros símbolos que, de algum modo, influenciaram os produtores da festa do Boi de Parintins.

A ênfase dada ao elemento alegórico está em sua visibilidade: são momentos de impacto, concorrendo no item "alegoria" e em outros, como "lenda amazônica" e "ritual indígena". Além disso, prendem a atenção do espectador, resultando em "calorosos debates", excelentes para discutir as diversas concepções alegorizadas do elemento indígena.

Diante do exposto, o objetivo deste estudo é compreender a construção do indígena no imaginário alegórico parintinense. Para tanto, historia-se a alegorização do Festival, esboça-se a concepção do indígena para a criação do elemento alegórico e evidencia-se como tais processos imbricam-se para a recriação anual da festa. Dado o uso de alegorias em todo o desenrolar da festa, fez-se um recorte da análise durante o desenvolvimento de um ritual indígena, por entender-se ser um momento onde o elemento em análise aparece com maior expressividade e pelo poder de síntese que um artigo científico requer. 


\section{Metodologia}

Entendendo a diversidade $\mathrm{e}$ complexidade do campo da cultura amazônica, o estudo foi desenvolvido no território da "vivência" e da possibilidade de aquisição de informações através do contato direto com as pessoas que produzem e experimentam o fenômeno. Isso implicou buscar auxílio metodológico na Etnografia, cujo objetivo, segundo Geertz (1989), não se limita a selecionar informantes, levantar genealogias ou simplesmente transcrever textos, dentre outras técnicas que determinam este exercício, mas consiste numa hierarquia estratificada de aspectos significantes em torno dos quais os atos são produzidos, percebidos e interpretados, e sem os quais eles, de fato, não existiriam.

A experiência em campo foi desenvolvida de um local privilegiado. Um dos autores ocupa o cargo de presidente do Conselho de Artes em uma das agremiações e, o outro, acompanha o festival há mais de dez anos, enquanto espectador. Assim, o olhar compreensivo foi desenvolvido por meio do diálogo entre espectador e criador da festa. Acredita-se que isso ajudou sobremaneira a sanar possíveis "pontos cegos", equilibrando razão e emoção.

O estudo foi empreendido nos anos de 2015 e 2016, sendo o recorte de uma dissertação de mestrado. Pelo fato de um dos autores ser presidente do Conselho de Artes, a cidade de Parintins foi alvo da investigação nesse período de tempo, com total acesso aos materiais de uma das agremiações, no caso, o boi-bumbá Caprichoso. Por questões de rivalidade provavelmente não teríamos acesso ao material da outra agremiação -, o boi-bumbá Garantido não foi alvo do presente estudo. Neste artigo, dadas as características desse tipo de produção e da amplitude do estudo original, foi escolhido um ritual indígena para análise.

Breve histórico do elemento alegórico em Parintins: dos usos e finalidades 
Introduzidas no Festival

Folclórico de Parintins no final da década de 1970, pelo artista Jair Mendes, influenciado pelos carros alegóricos dos desfiles das Escolas de Samba cariocas, as alegorias tornaram-se um dos principais atrativos do espetáculo dos bumbás e também uma das obras mais ambiciosas tanto do ponto de vista técnico e estético quanto da criatividade. As alegorias são produzidas com materiais leves, como o isopor e papelão, mas também envolvem outros mais pesados e resistentes, como o ferro galvanizado, necessário para garantir a sustentação das estruturas. Em geral, suas enormes proporções descansam sobre rodas, que permitem sua locomoção, que é impulsionada basicamente pela força humana.

O pesquisador cultural e especialista em Escola de Samba Carioca Fernando Pamplona diz que não há comparação, da apresentação do boi-bumbá ser realizado numa "arena", enquanto o carnaval é um "cortejo". O que acontece em Parintins, entretanto, é que o Festival Folclórico assumiu uma "grandiosidade" e, na "grandeza", seria comparável com as Escolas de Samba.

(BRAGA, 2002, p. 49)

Como assinala Cavalcanti (2007), nas duas festas (boi-bumbá e carnaval), a presença e os efeitos produzidos pela ação das alegorias são notáveis. Entretanto, a organização social e a técnica de sua confecção, a dinâmica festiva na qual se inserem e, em especial, suas funções, seus usos e sentidos na performance ritualística propriamente dita, diferem em muito nos dois casos.

Apresentadas pela primeira vez no Festival Folclórico, em 1979, as alegorias foram julgadas como item em 1983 e, desde 2005, compõe a lista de itens oficiais, sendo definidas no atual regulamento do festival (2015, p. 12) como "Estruturas artísticas que funciona como suporte cenográfico para apresentação". De acordo com esse mesmo documento, o julgamento das alegorias considera os seguintes critérios: "Méritos: Beleza, criatividade, originalidade e grandiosidade.

Elementos Comparativos: Acabamento, execução, funcionalidade, estética e 
porte" (REGULAMENTO..., 2015, p. 12).

As alegorias dos bumbás de Parintins são compostas por um conjunto de módulos que se articulam em cena aberta durante a performance. Nos primeiros anos de festival, elas eram simples e, comparadas às de hoje, pareciam miniaturas. Ao longo dos anos, foram sendo redimensionadas e ganhando, por conseguinte, maior espaço nas apresentações. Quando voltamos ao passado, observamos a grande distância que há entre uma produção e outra.

Os artistas buscaram alternativas para dar movimentos às suas criações e, assim, alcançaram movimentos feitos manualmente ou, em alguns casos, com adaptações realizadas em um motor elétrico. Para os movimentos manuais, são utilizadas cordas de sisal ou nylon, enroladas em manivelas, com o objetivo de proporcionar movimentos ascendentes e descendentes em alegorias de aves, insetos, figuras humanas e outros.

Além desse fato, notável por si só, o que há de especialmente interessante nas alegorias é que estas não são meras estruturas que ambientam a ação ritualística, mas cenários vivos, molduras vivas, elas mesmas atuantes, de modo magnífico, na sequência de ações que, mais do que acompanhar, integram e realizam (Figura 1). Cavalcanti (2002) assinala que esses cenários vivos, que se instalam e realizam seu destino expressivo completo na arena, pontuam a apresentação com momentos de clímax extático e produzindo, nos participantes - todos, a um só tempo, comportando-se como brincantes e espectadores -, 0 efeito de movimento acima indicado. Nesse sentido, houve espaço para o surgimento do elemento indígena, conforme observado por Nogueira (2014, p. 26):

O "artista de boi" inseriu os índios amazônicos no espetáculo do boibumbá por meio da recriação das suas culturas, que passaram a existir além das aldeias e dos tratados antropológicos que circulam nas universidades. Assim, é possível compreender o Boi-Bumbá de Parintins como veículo de comunicação e conscientização de aspectos culturais, manifestos e latentes, de povos que viveram e vivem 
historicamente suas contradições. Do ponto de vista da abordagem artística, o espetáculo de boibumbá expressa um diálogo multicultural, onde índios, brancos, negros e mestiços celebram o desejo da convivência harmoniosa. $\mathrm{O}$ boi-bumbá representa, por isso, a possibilidade de sobrevivência das tradições de cada uma dessas culturas no mundo globalizado. Tradição e modernidade, nesse caso, são fluxos culturais que interagem ou se misturam permanentemente.

Jair Mendes foi mestre de vários artistas plásticos que, atualmente, estão vinculados aos bumbás, entre os quais, Vandir Santos, Juarez Lima, Cansanção, Marquinhos, além dos próprios filhos de Jair, Teco Mendes e Jairzinho Mendes. Por isso, comumente é chamado de "Mestre Jair" no contexto parintinense, sobretudo, pelos artistas atuantes no boi que reconhecem a importância de sua contribuição.

Hoje, os produtores dos bumbás, especialmente os artistas, mas também o público reconhecem, na "Alegoria", a estrutura artística mais importante do festival, tendo grande utilidade na potencialização das encenações das Lendas
Amazônicas, Celebração Folclórica, Figuras Típicas Regionais e Rituais, sem necessariamente descaracterizar a sequência narrativa tradicional do espetáculo.

As constantes idas de artistas para trabalhar nas Escolas de Sambas do Rio de Janeiro e de São Paulo levaram o conhecimento acumulado disputa dos bumbás para os galpões das Escolas de Sambas cariocas e paulistas, descortinando um fascinante caso de troca e empréstimo cultural entre as duas festas, que se mantêm em pleno curso.

Nesse processo, o artista parintinense se apoderou de elementos do carnaval carioca, como o carro alegórico que, no festival, passou a chamar-se alegoria. No Festival Folclórico de Parintins, as alegorias são de fundamental importância nas apresentações dos bumbás, responsáveis pelas composições dos cenários, construídas em proporções gigantescas, geralmente fazendo alusão a representações de pássaros, animais, répteis, personagens mitológicas, lendas, cotidiano, imaginário indígena e dos ribeirinhos. São surpreendentes, articuladas, repletas de imaginação. Nessas alegorias, fazem-se referências à criação dos bumbás, fatos históricos ligados a região, cotidiano dos seus habitantes, figuras 
mitológicas, homenagem a pessoas de importância para a região, etc. (SILVA, 2005, p. 30)

A primeira alegoria foi apresentada pelo Boi-Bumbá Garantido, no Festival Folclórico de Parintins do ano de 1979. Segundo relatos de seu autor, a alegoria media $3 \mathrm{~m}$ de altura por $3 \mathrm{~m}$ de largura, com $1,50 \mathrm{~cm}$ de profundidade, e era produzida envolvendo materiais como madeira, plástico, papelão, pano e tinta. Era um painel com um panorama amazônico, onde surgia da vitóriarégia a figura da lara, a mãe d'água. Nesse quadro, os pássaros voavam, o canoeiro andava em sua canoa com movimentos feitos através de linhas. A alegoria se locomovia com rodas de velocípedes, um trabalho que havia sido feito em absoluto sigilo. Essa apresentação teve bastante êxito, pois se tratava de uma novidade.

$\mathrm{Na}$ década de 1980, aconteceram importantes mudanças e adaptações, como a transferência do festival para o Estádio Tupy Cantanhede, o "tabladão", e, posteriormente, para 0 Anfiteatro
Messias Augusto, local onde foi construído o atual Bumbódromo. As alegorias foram influenciadas por esse movimento, que envolveu espaços cada vez maiores, e conheceram uma alteração gradativa de suas dimensões e também de sua complexidade. Durante um bom tempo, foram construídas inteiramente com madeira, compensado, cipó, papelão, plástico, tinta, pano e materiais regionais, sempre nos formatos de caixas, ou tablados, pois a madeira não permitia flexibilidade e nem a produção de curvas ou objetos sinuosos.

Com esculturas de bonecos confeccionadas com caixas de papelão, doadas pelos comerciantes da cidade, as alegorias representavam figuras das lendas amazônicas, como o gigante Juma (Figura 1), o Jurupari e a Cobra Grande. As estruturas representavam elementos que integravam e caracterizavam a paisagem da região, como lagos, igarapés, pescadores e agricultores. Alegorias com módulos únicos, um pouco maior que as primeiras, que mediam em torno de $5 \mathrm{~m}$ a $6 \mathrm{~m}$ de 
comprimento, por $3 \mathrm{~m}$ de largura, eram transportadas em caminhão e carregadas para dentro da arena pelas equipes dos artistas que confeccionavam e pelas equipes de apoio.

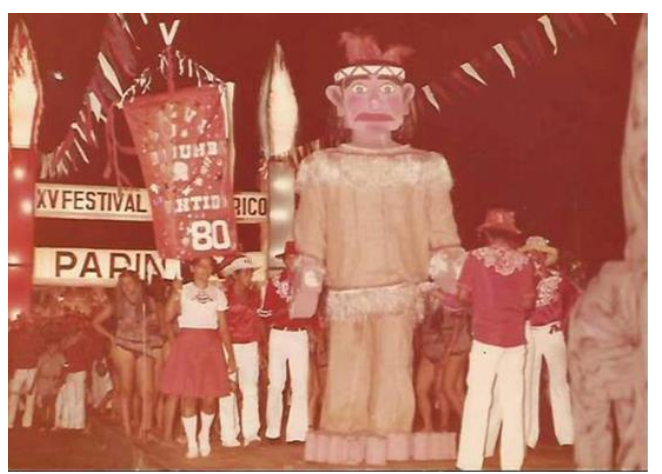

Figura 1 Lenda do Gigante Juma. 1980. Foto: Vandir Santos.

Nesse período, a figura do carpinteiro ganhou importância para a confecção das alegorias. Com o conhecimento do seu ofício, ajudava na escolha das madeiras mais apropriadas para cada trabalho, assim como no manejo desses materiais. Nessa região, há madeiras muito pesadas e duras, que dificultam a fixação de prego. Os carpinteiros foram importantes para esse processo, dividindo responsabilidades com outros profissionais, inclusive, com os artistas autores das obras. Eram os primeiros na formação das equipes de artistas para confecção dessas alegorias. Mais tarde, com o advento do emprego do ferro nas estruturas, os carpinteiros passariam a atuar de maneira colaborativa com os soldadores.

Pela inventividade e criatividade de seus artistas, o Boi Garantido se manteve sempre à frente do seu concorrente, que fazia de tudo para apresentar algo novo. $E$, por muitos anos, o boi das cores vermelho e branco levou vantagem. Entretanto, no fim de 1985, Jair Mendes aceitou o convite do Boi Caprichoso, deixando, em aberto, seu espaço no Garantido. Então, no ano seguinte, Vandir Santos, que era seu auxiliar desde 1978, assumiu o comando artístico nas alegorias no Garantido, apresentando trabalho inovador, com quatro módulos, que juntos criaram volume em sua composição. Com materiais regionais naturais, a obra intitulada "A grande farinhada", tinha espaço para mais de quinze pessoas apresentando o plantio, a colheita e a produção da farinha, atividade agrícola desenvolvida pelo caboclo da região. 
A técnica foi adotada, nos anos seguintes, pelas agremiações participantes, dando novo rumo para as alegorias. Nas suas apresentações, os bumbás procuravam apresentar a cênica. As alegorias foram ganhando potencialidades e volumes, como afirmou o próprio Jair Mendes, durante conversa. Já na ocasião das primeiras alegorias, suas invenções apontavam para a grandeza e sofisticação que caracterizariam estas realizações posteriormente.

Jair Mendes retornará para o Garantido e Juarez Lima despontará como um dos principais artistas do Caprichoso. Após sua atuação junto ao carnaval carioca, o artista trouxe, em 1991, a novidade do ferro. A escultura de uma onça foi um dos primeiros trabalhos realizados: grandiosa, toda esculpida em ferro, e, mesmo sem movimento, causou admiração nos presentes no Bumbódromo. Juarez, por sua ousadia e criatividade, deu nova visão ao trabalho estético no conceito de alegoria no Festival Folclórico de Parintins, fazendo que outros artistas trilhassem esse caminho no decorrer dessa evolução.

Nos anos seguintes, a evolução das alegorias foi inevitável. Os artistas, de posse das estruturas metálicas, começaram a fazer obras mais ousadas, com maior segurança para as apresentações. As esculturas, cada vez mais altas e resistentes, tornavam mais leves os módulos, facilitando sua locomoção até a área de concentração no Bumbódromo. Os produtores dos bois tiveram a preocupação de encomendar roldanas mais resistentes para suas alegorias para evitar quebra das peças no translado.

A introdução do ferro como base para as estruturas, que, até então, eram feitas de madeira deu início a um novo tempo na produção das alegorias. Introduziram-se fantásticos movimentos, num impulso ainda hoje em atividade, aprimorando cada vez mais os trabalhos.

\section{O indígena no imaginário} alegórico do Boi-Bumbá de Parintins: o Ritual Indígena 
Para falar do indígena no imaginário alegórico, escolheu-se um momento de grande expressividade, o Ritual Indígena. O item foi inserido recentemente no contexto das apresentações, tornando-se um marco no festival. Absolutamente carregado de signos do universo mítico indígena, este item retrata não somente o simbolismo fantástico da mitologia desses povos, mas também abrange, de maneira complexa e ampla, seus conhecimentos e sua maneira de se perceber no mundo, sua fé e suas relações sociais nas mais variadas dimensões. No espetáculo, a apresentação do item constitui o momento de culminância apoteótica, geralmente, $o$ ato final da festa. Mas não é necessariamente o último, podendo aparecer no início do espetáculo.

Sobre o tema, o regulamento atual do Festival Folclórico de Parintins (2015) define o item como recriação de rito xamanístico. Deve apresentar fundamentação por meio de pesquisa. Qualifica-se pela apresentação de teatralização, criatividade, beleza, originalidade e efeitos e é comparado com o rival por meio da fidelidade à toada cantada na apresentação do ritual, desenvolvimento, beleza e encenação, observada a sua fundamentação

(pesquisa/referências) dentro da folclorização do boi de arena.

A apresentação do boi, por si só, já é um ritual. Inicia com a organização, a maneira de como os itens se apresentam, até a saída do grupo do Bumbódromo. No entanto, um ritual como item é julgado de acordo com as cerimônias propostas pelo Conselho de Arte (Boi Caprichoso) ou Comissão de Arte (Boi Garantido) e acontece em uma "Alegoria", contendo vários módulos e que é montada no centro da arena.

Durante o Ritual, podemos entender e sentir alguns mistérios da selva, como seres fantasmagóricos, danças, tribos, lutas, mortes, animais, a natureza, o Pajé e, algumas vezes, a chegada da figura feminina mais emblemática da tribo: a Cunhã Poranga.

O significado do ritual vivido em Parintins hoje somente pode ser entendido como marco do sistema simbólico, que inicia com os 
processos de criação artística desenvolvidos na cidade para o auto do boi-bumbá no início do século XX e chega, aos nossos dias, sob forma de festival. Então, o sentido de ritual e arte no qual abordamos, carrega a herança da ancestralidade parintinense indígena, africana negra e hierática cristã, como base para o ritual performático como um sistema cultural de comunicação simbólica que fundamentam o Festival Folclórico de Parintins (BIRIBA, 2005, p. 217).

Em conversa, o artista Ito Teixeira (alegorista e um dos responsáveis pelo desenvolvimento do item em comento) fez o seguinte esclarecimento:

Essa ideia nasceu porque eu, quando era pequeno, adolescente, de 12, 14 anos, lia muitos livros de índio, Tarzan, muitas revistas em quadrinhos do Texas. Eu sempre com aquela ideia de que o índio pega o homem branco pra comer, porque os adultos passam muito essa ideia pra gente. E quando eu comecei a fazer essas apresentações não tinha noção de onde eu ia chegar com isso, que isso ia ser transformado no item de ritual. A primeira apresentação foi em 1983. Ela começou com uma apresentação que desenvolveu apenas uma moça e a minha tribo, a tribo dos Carajás, simples aparentemente, mas de grande repercussão pública de arena. Nós colocamos uma menina em meio de um círculo de fogo e dançamos em volta com umas tochas. Esse círculo no centro da arena ficou a fumaça que saia das tochas. Os índios gritando em volta. Isso deu um efeito bastante interessante. Daí por diante, eu comecei a fazer apresentações muito parecidas com essa, com a minha tribo. Mas, hoje, eu não envolvi só uma tribo, mas varia de tribos. Aí, eu comecei a fazer apresentações conjuntas, levando várias tribos, com estilo envolvendo sempre fogo e fumaça, dando sempre efeitos significativos na arena. Aí, em 1988, eu tive a ideia de fazer umas maquetes e eu coloquei umas rampas na arena do bumbódromo e os índios iriam subir e descer, subir e descer, criando certo efeito e umas arquibancadas onde os índios iriam ficar para uma espécie de torcida para as apresentações. Eu comecei a criar um cenário para as apresentações de rituais. Colocamos também um tablado que foi colocado o pajé, que a primeira vez foi o Waldir Santana. Eu convenci o Waldir a dançar como Pajé, pois os pajés dos bois eram muito estáticos e Pajé tinha que ser bailarino e dinâmico. $E$, depois que eu criei esses momentos alegóricos, criei os tablados, o índio lá no meio e o fogo em volta e o Pajé dançando, isso foi praticamente o marco dessa apresentação coletiva que configurou o Ritual. E, dentro dessa dinâmica do ritual que foi criada, nós trouxemos para dentro do ritual a Cunhã Poranga e o Pajé. Eles deixaram de fazer apresentações solo para se apresentarem juntos. Aí, esse foi um contexto montado, trazendo primeiro o Pajé e, depois, a Cunhã Poranga para o Ritual. Foi uma sequência e tudo ocorreu por acaso, nada que a gente planejasse que ia ter um sucesso ou não, que era livre ou não e eu 
tinha certa liberdade e confiança dos diretores do Garantido. E partiu pela criação das tribos e nós ganhamos uma liberdade não de pedir permissão 'pra' fazer mais de fazer e até analisar o que íamos fazer. Daí veio todo o sucesso. Eles depositavam confiança na gente, tínhamos liberdade. O Ritual começou em função disso, com a apresentação da tribo dos Carajás e, depois, unindo várias tribos e, a cada ano, fazendo as apresentações diferentes, no solo, no tablado de madeira e, posteriormente, com as alegorias que começamos a fazer e aí virou um fato novo. Foi o Ritual que começou a dar dimensão às alegorias $e$ à quantidade de módulos na arena.

O Garantido deu início ao Ritual. Era uma apresentação que só o Garantido fazia. Como não era item, mas fortalecia a apresentação, o Caprichoso percebeu que estava levando desvantagem, então, aderiu ao Ritual. Quando o Caprichoso começou a fazer o Ritual, em uma das reuniões que houve na antiga tribuna, que era discussão do regulamento, eu chamei o Simão, - Karu e sugeri que o Ritual, que já estava consolidado, passasse a ser item. Isso ocorreu lá pelo ano de 1990. Eu tive a ideia de usar a vela na arquibancada e apagar as luzes. Esse foi outro marco na história do festival, uma maneira diferente de apresentar o boi. As alegorias começaram a vir com luzes. A galera com luzes nas mãos.

Nogueira nos oferece outras contribuições para o entendimento da importância dos rituais nas apresentações dos bumbás de

Parintins:

Os rituais indígenas e as toadas de temas amazônicos ganham força e espaço nos bois-bumbás no final da década de 1980, época em que o Brasil se preparava para realizar, em cooperação com a Organização das Nações Unidas (ONU), a ECO-92, a reunião de líderes mundiais e ecológicas que discutem prováveis soluções para o aquecimento global. A ECO-92 é um dos desdobramentos das reuniões do gênero que se iniciaram com a Cúpula da Terra, realizada em 1970, na cidade de Estocolmo, capital da Suécia. Nos rituais espetacularizados dos boisbumbás, os heróis e demiurgos que povoam 0 imaginário das populações dos rios e das florestas amazônicas passaram a ser recorrentes. $O$ seringueiro $e$ ecologista Chico Mendes, assassinado em 1987, a mando de criadores de gado, aparece como homenageado em várias ocasiões nos dois bois-bumbás. O seringueiro tornou-se o mártir dos povos da floresta, a exemplo de Lampião, entre as populações pobres do Nordeste. (NOGUEIRA, 2014, p. 45)

Também é importante destacar, como destacado pelo Regulamento, a necessidade da toada para o desenvolvimento do ritual quando de sua apresentação e julgamento. Por isso, apresenta-se aqui a letra da toada do item a ser estudado: 
Eu vejo espíritos que voam/ Em sarinkaveni/ eu vejo/ Eu vejo fogo, destruição/ Eu vejo fogo, desolação/ Eu vejo fogo, desolação/ Eu vejo fogo/ Eu vejo fogo. Viajei/ Eclipse do mundo, labirinto soturno/ Devaneio derradeiro do sonho profundo/ Em dimensões cataclísmicas/ Andei/ Em terras sucumbidas, ruínas, ilusões/ Miragens e asssombrações, miragens e assombrações/ No abismo do centro da terra/ Morada das feras/ No transe de kamaramphi enfrentei/ Ceifadores, ceifadores/ Animais do além sobrenaturais/ Hordas, legiões de aprisionados/ Temporais de seres mutilados/ Que tomam forma de bichos/ Guardiões de pesadelos/ Onças de fogo vagueiam na escuridão/Aves em chamas, exorcismo na libertação/Expulsei entidades kamari de sarinkaveni/ $\mathrm{Na}$ transcendência, o etéreo se faz animal/ A lua soturna devora as almas kamikari/ Eu vejo fogo, eu vejo fogo/ Eu vejo/ Eu vejo espíritos que voam/ Em sarinkaveni eu vejo/ Sarinkaveni é tormenta/ Inferno ashaninka. Kamaranphi, o inferno ashaninka (Guto Kawakami;
Geovane Bastos; Arthur Nascimento - Caprichoso, 2015)

A toada tenta descrever 0 complexo ritual Kamaranphi, utilizado aqui como referência para discussão. Cânticos, danças e pajelanças do Pajé Ashaninka anunciam o início do Ritual Kamaramphi. Acreditam os índios do rio Amônia que, quando a lua canibal devora o sol no eclipse solar, os portais de Šarinkavéni, o inferno Ashaninka, também conhecido como "a gigante gaiola das feras sobrenaturais", se abrem, dando passagem ao caos e à destruição do cosmos Ashaninika. O medo toma conta da aldeia. Rezas, gritos e choros de desespero são ouvidos. Somente o Xamã Sheripiari, - matador astral das feras de Šarinkavéni, sob o efeito das folhas de coca e da ayahuasca, transcende ao além mundo, no místico ritual Kamarampi. Lá, o poderoso pajé combate os tenebrosos espíritos Kamari, aves em chamas, onças de fogo e criaturas aladas, que se alimentam das almas dos Ashaninka mortos. A toada e a pesquisa foram retratados na alegoria abaixo (Figura 2). 


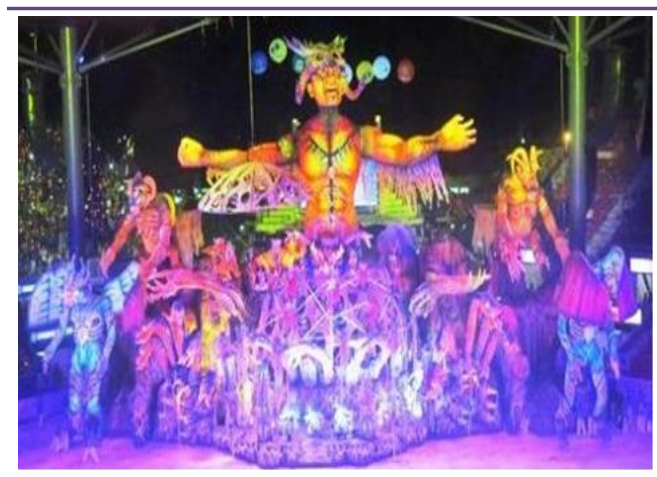

Figura 2 Execução do Ritual Kamaramphi. 2015. Foto Alexandre Vieira

Como já salientado e após apresentação da imagem, conseguese perceber porque a apresentação das alegorias constitui um dos momentos mais esperados do espetáculo. Neles, os seres da floresta ganham vida e caminham na arena, movimentando-se com grande realismo. No Ritual, a cosmogonia, etiologia e a escatologia indígena são apresentadas numa recriação apoteótica, tornando o personagem Pajé o protagonista do universo indígena do Boi-Bumbá de Parintins.

No contexto da festa parintinense, a ideia de "índio" passa por uma ressignificação que, embora conservando alguns estereótipos, distanciou-a, cada vez mais, do sentido pejorativo e reducionista que, há muito a impregnava, inclusive, na convivência diária dos amazonenses, que costumava usar o termo significando atraso, selvageria e ignorância. Agora, o elemento indígena demonstra uma carga romântica de heroísmo. Segundo Cavalcanti (2002, p. 129), "é notável que esta festa popular o faça a partir de uma perspectiva que revisita e reinterpreta 0 herói trágico do romantismo literário brasileiro - 0 'dono do país' antes da chegada de europeus e africanos, transformandoo no antepassado mítico-histórico nacional". Isso nos permite pensar a temática indígena como propulsora de uma reeducação dos temas abordados no espetáculo, e não apenas este, mas de fatores que, por meio da festa, despertam o caráter da autocriticidade do pensamento sobre a sociedade e a cultura do homem amazônico. Também nos permite constatar que o alegórico, imaginado e realizado pelo parintinense, expressa como ele, de alguma forma, pensa a si mesmo e se visualiza no índio e no caboclo, representado em sua própria obra. Há uma dinâmica de identidade/identificação que ajuda a pensar, inclusive, a importância da 
arte enquanto produtora de discurso sobre si mesmo e sobre o outro.

\section{Considerações finais}

A ancestralidade celebrada no Festival Folclórico de Parintins, especialmente a indígena, destacase em inúmeras peculiaridades dos rituais que acontecem no decorrer da construção anual de cada espetáculo. São dançadas e cantadas as toadas que revisitam narrativas e entes do sobrenatural, elementos que constituem a cultura indígena e cabocla. Das toadas e pesquisas, surgem as alegorias, as quais expressam concepções do imaginário indígena, mediadas pelo trabalho dos bumbás, em uma perspectiva de teatralização.

O Boi-Bumbá de Parintins tem função educativa na arte e, sobretudo, na restauração da cultura indígena, especialmente ao fazer uma autorrevisão da identidade por meio do espetáculo, recriando e materializando, dando sentido, até mesmo sinestésico, aos brincantes que, no subconsciente, vivem uma catarse renovada a cada ano, como herança adormecida e existente em um bairrismo e no orgulho caboclo.

O imaginário indígena, exaltado nas toadas e nas apresentações das associações culturais, fez a festa ultrapassar as fronteiras da região. Ainda que de maneira espetacularizada em sua engrenagem comercial, tal fato adquire um contorno de viés narrativo, o que dá às alegorias grande importância, por serem os elementos que, em grande parte, ajudam a narrar elementos simbólicos do universo indígena. Também se nota que a comunidade identifica-se como parte integrante do que é apresentado e representado pelos bumbás, em uma importante tônica de representatividade, em que o índio não é mais um elemento externo narrado por outrem, mas parte de "mim" (espectador), em uma tônica de identidade/identificação.

Pensa-se ter obtido êxito em evidenciar a concepção do indígena no imaginário alegórico dos bois. Entretanto, crê-se ser necessário que mais pesquisas sejam empreendidas, analisando a festa 
sob outros vieses, de modo a tentar apreender, dentro do possível, a complexidade do imaginário aqui descrito, em outros anos, com outros referenciais teóricos e sob outros olhares. A festa estimulou 0 surgimento de um novo olhar sobre o índio da Amazônia e sua cultura, partindo para uma reconstrução de novos valores da identidade regional. Assim, compreende-se que um leque de opções de pesquisa abre-se para se trabalhar com a temática.

Conclui-se, com foco no evidenciado neste artigo, que a construção do indígena no imaginário alegórico dos bois-bumbás de Parintins redundou na mescla do parintinense indígena e construtor da festa, tornando a visão do índio romantizada e espetacularizada simultaneamente. Esta constatação central redundou em uma festa em que 0 alegórico expandiu-se em proporções e dimensões, estando a grandiosidade desse elemento atrelada ao tamanho que os artistas pretendem dar à potência de sua própria representatividade.

Recebido em 27/07/2018 Aceito em 18/09/2018

\section{Referências Bibliográficas}

BIRIBA, Ricardo Barreto. Parintins cidade ritual: boi-bumbá, performance e espetacularidade. 2005. 385 f. Tese (Doutorado em Artes Cênicas) - Escola de Teatro, Universidade Federal da Bahia, Salvador, 2005.

BRAGA, Sergio Ivan Gil. Os Bois Bumbás de Parintins. Rio de Janeiro: Funarte/ Editora da Universidade do Amazonas, 2002.

CAVALCANTI, Maria Laura Viveiros de Castro. Brincando de Boi: a força dos ritos nos bois-bumbás de Parintins. Ciência Hoje, Rio de Janeiro, v. 40, n. 240, p. 18-25, ago. 2007.

CAVALCANTI, Maria Laura Viveiros de Castro. $O$ indianismo revisitado pelo boi-bumbá: notas de pesquisa. Somanlu, Manaus, v. 2, número especial, p. 127-134, 2002.

GEERTZ, Clifford. A interpretação das culturas. Rio de Janeiro: Guanabara Koogan, 1989.

NOGUEIRA, Wilson. Boi-Bumbá: imaginário e espetáculo na Amazônia. Manaus: Valer, 2014.

REGULAMENTO do festival folclórico de Parintins Concurso de Bumbás 2015-2016. Manaus, 12 mar. 2015. Disponível em: <https://issuu.com/boicaprichoso/doc s/ regulamento_do festival folcl_rico> . Acesso em: 13 jun. $201 \overline{8}$.

RIBEIRO, Berta. O índio na história do Brasil. São Paulo: Global, 2009.

SILVA, Maria Helena Rodrigues. BoiBumbá de Parintins: arte e significação. 2005. 176 f. Dissertação (Mestrado em Artes) - Instituto de 
Artes, Universidade Estadual de

Campinas, Campinas, SP, 2005.

Moringa Artes do Espetáculo, João Pessoa, UFPB, v. 10 n. 1, jan-jun/2019, p. 49 a 66 